\title{
Comparison of the time required for removal of intraradicular cast posts using two Brazilian ultrasound devices
}

\section{Manoel Brito-Júnior(a) \\ Janir Alves Soares ${ }^{(b)}$ Suelleng Maria Cunha Santos ${ }^{(c)}$ Carla Cristina Camilo(a) Gil Moreira Júnior ${ }^{(d)}$}

(a) Professor of Endodontics; (c) MSc student in Health Sciences - State University of Montes Claros (UNIMONTES), Montes Claros, MG, Brazil.

(b) Professor of Endodontics, Federal University of the Valleys of Jequitinhonha and Mucuri (UFVJM ), Diamantina, MG, Brazil.

(d) Assistant Professor, Dental School, University of Itaúna, Itaúna, MG, Brazil.
Corresponding author:

Manoel Brito Júnior

Rua Boa Vontade, 227 - Santa Rita

Montes Claros - MG - Brazil

Cep: 39400-415

E-mail: manoelbritoir@gmail.com

\begin{abstract}
The aim of this in vitro study was to compare the time required for removal of intraradicular cast posts cemented with zinc phosphate (ZF) or glass ionomer cement (GIC), using two Brazilian ultrasound devices (BUD). Seventy two human inferior premolars with single root canals were sectioned transversally at the cementoenamel junction. In each specimen, the root canal was endodontically treated, the post space was prepared to a depth of $9 \mathrm{~mm}$ and the canal was molded to obtain a post impression. After the casting procedures, the posts were randomly distributed into 2 groups $(n=36)$ according to the luting material used: G1 - ZF and G2 - GIC. The tooth and luted post set was then embedded in an acrylic resin block. The groups were then divided into 3 subgroups $(\mathrm{n}=12)$ according to the ultrasound device used: A - Enac (Osada Electric, Japan), used as a control group; B - Profi II Ceramic (Dabi Atlante, Brazil) and C - Jet Sonic Satelec (Gnatus, Brazil). The posts were submitted to the vibration process with maximum power set on all surrounding surfaces. Time of application was recorded with a chronometer until complete post dislodgment, and the data were analyzed by the ANOVA test $(\mathrm{p}<0.05)$. The averages required for post removal in G1 and G2 were respectively 41.42 and 92.03 seconds, with significant statistical difference $(\mathrm{p}=0.001)$. No statistical difference was observed among the three ultrasound devices $(\mathrm{p}=0.088)$, and the BUD presented a performance similar to that of the international gold standard device (Enac). Moreover, the type of luting agent had a greater influence on the time required for post removal than the origin of the ultrasonic unit.
\end{abstract}

Descriptors: Post and core technique; Endodontics; Ultrasonics. 


\section{Introduction}

Intraradicular retainers are a valuable resource in the prosthetic rehabilitation of endodontically treated teeth with extensive coronal destruction, due to the mechanical fixation and increased resistance they provide to artificial crowns.

Nevertheless, in the case of treatment failure, an endodontic retreatment should be performed through cleaning, shaping, disinfecting and filling the root canal system since this is a conservative and efficient way to treat periapical injuries. ${ }^{1-3}$ In these circumstances, intracanal post removal often represents an obstacle to endodontic retreatment. ${ }^{2,4-8}$

During the removal of intraradicular posts, which is commonly a complicated task for both patient and professional, some factors must be considered such as the remaining volume and integrity of tooth tissue, post retention and the technology used in this procedure. It is necessary to establish an appropriate plan to avoid irreversible damages such as root fractures. ${ }^{6,9-15}$ The techniques and instruments that have been advocated for post removal include burs to drill the post, devices that grasp the posts so that they can be pulled out of the root and ultrasounds. ${ }^{1,8}$

Ultrasonic devices have been used for the removal of intraradicular posts for decades, confirming the efficiency and safety of this method. ${ }^{4,5,16,17}$ Ultrasonic vibration transfers intense mechanical waves to the cementing layer between the metallic post and the root canal walls, dislodging the post as a result. ${ }^{4}$ In addition, lower ultrasonic vibrations applied to the dental structure during post removal save time and preserve root integrity. $5,9,10,13,16,18$

Ultrasonic units are either of a magnetostrictive type, in which the electromagnetic energy is converted to mechanical energy, or of a piezoelectric type, where the deformation of a crystal is converted to mechanical oscillations. ${ }^{11}$ The magnetostrictive ultrasound has the inconvenience of generating intense heat during use. In contrast, piezoelectric devices generate mechanical waves with high-frequency stability, ${ }^{5}$ transmitting a minimal residual heat to dental structures. ${ }^{2,3,13,15}$ This is the reason why piezoelectric equipment is more widely used in clinical practice..$^{2,3,12}$
For a long time, Enac-Osada, the Japanese-manufactured piezoelectric ultrasound, has been the most widely used apparatus for post removal. , $, 4,13,18-21$ In Brazil, ultrasounds with piezoelectric characteristics were recently introduced by the manufacturers Dabi Atlante and Gnatus. However, studies on their use and performance for the removal of intracanal posts are still scarce.

This in vitro study aimed to compare the time required for removal of intraradicular cast posts cemented with zinc phosphate or glass ionomer cement, using two Brazilian piezoelectric ultrasound devices.

\section{Material and Methods}

Seventy-two extracted lower premolars with single root canals, without endodontic treatment and with well preserved coronal and radicular structures were selected from the tooth bank of the Dental School of the State University of Montes Claros, MG, Brazil. The teeth were previously examined under light and x10 magnification. Those with cracks or corono-radicular fractures were discarded.

Coronal access was initially performed with a \#1557 tapered carbide bur (S.S. White Dental products, Rio de Janeiro, RJ, Brazil) at high speed, followed by a compensatory wear with an Endo-Z bur (Dentsply/Maillefer Instruments, Ballaigues, Switzerland). Manual root instrumentation was performed with K-files (Dentsply/Maillefer, Ballaigues, Switzerland) and \#2-4 Gates-Glidden drills (Dentsply/Maillefer, Ballaigues, Switzerland) using the adapted Oregon technique. ${ }^{19}$ The root canals were irrigated with a $2.5 \%$ sodium hypochlorite solution (Biodinâmica Produtos Químicos Ltda., São Paulo, SP, Brazil) between each instrument followed by smear layer removal with a $14.3 \%$ EDTA solution ( $\mathrm{pH}$ 7.4; Odahcam-Herpo Produtos Dentários, Petrópolis, RJ, Brazil) for 3 minutes and a new irrigation with sodium hypochlorite. After drying, the root canals were filled with gutta-percha cones (Odous, Belo Horizonte, MG, Brazil) and Pulp Canal Sealer-EWT cement (Kerr Corporation, Orange, CA, USA) using the thermomechanical condensation technique.

Each tooth was horizontally sectioned at the 
cementoenamel junction with a carburundum disc (Dentorium, New York, NY, USA) keeping a root length of $15 \mathrm{~mm}$. Post spaces were subsequently prepared with \#3 Largo burs (Dentsply/Maillefer, Ballaigues, Switzerland) to a depth of $9 \mathrm{~mm}$ and a diameter of $1.1 \mathrm{~mm}$ to standardize the length and apical diameter of the post preparation. The root canals were molded with chemically activated acrylic resin (Duralay, Reliance Dental, Worth, IL, USA) and the prosthetic posts were cast in copper-aluminum alloy (Goldent L.A., AJE, São Paulo, SP, Brazil).

Sequentially, the specimens were randomly divided into 2 groups of equal size $(\mathrm{n}=36)$ according to the luting materials, which were used following the manufacturer's instructions: G1 - Zinc phosphate (S.S. White Dental products, Rio de Janeiro, RJ, Brazil) and G2 - glass ionomer (Vidrion C; S.S. White Dental products, Rio de Janeiro, RJ, Brazil). The roots were isolated with solid vaseline and included in PVC tubes $(4 \mathrm{~cm}$ in length and $1 / 2$ inch in diameter) with self-curing acrylic resin (Clássico, Rio de Janeiro, RJ, Brazil). To check the post dimensions, each specimen was radiographed in orthoradial position. The extension of each post was measured in the radiographs with the aid of a millimetric scale, magnifying lens, and a light box. The specimens were stored at $37^{\circ} \mathrm{C}$ and $100 \%$ humidity.

After 7 days, the coronal portion of the post was abraded with \#1557 burs (S.S. White Dental products, Rio de Janeiro, RJ, Brazil) and \#3203 tapered diamond drills (KG Sorensen, Rio de Janeiro, RJ, Brazil) at high speed until the cement line was visualized. For appropriate adaptation of the ultrasonic tip, the coronal surface of the core was flatted with a \#1092 cylindrical diamond drill (KG Sorensen, Rio de Janeiro, RJ, Brazil).

The groups (G1 and G2) were then divided into 3 subgroups $(\mathrm{n}=12)$ according to the ultrasound device used: A - Enac (Osada Electric Co. Ltd., Tokyo, Japan) with an ST 09 tip (control group); B - Profi II Ceramic (Dabi Atlante, Ribeirão Preto, SP, Brazil) and C - Jet Sonic Satelec (Gnatus, Ribeirão Preto, SP, Brazil) (experimental groups). All ultrasonic devices were used with maximum power under water cooling by the same calibrated operator. During post removal, the ultrasonic tip of each device was maintained in the coronal region of the post with moderate compressive force and successively run over the buccal, mesial, lingual, distal, and incisal surfaces.

The time required for complete dislodgement of each post was recorded with a digital progressive chronometer (Tecnbrás Indústria e Comércio de Equipamentos Eletrônicos Ltda., São Paulo, SP, Brazil). The roots were removed from the acrylic resin and inspected under light and magnification to detect cracks and/or fractures. The values obtained were analyzed by the ANOVA test $(\mathrm{p}<0.05)$.

\section{Results}

The averages of the mesio-distal and cervico-incisal radiographic measures were: post length $=9.1 \mathrm{~mm}$, core length $=4.3 \mathrm{~mm}$, cervical core diameter $=4.9 \mathrm{~mm}$ and post cervical diameter $=2.8 \mathrm{~mm}$.

Overall, the posts were removed faster with Enac and Profi II in both groups. For the Enac groups (control), the time ranged between 17 and $120 \mathrm{sec}-$ onds (mean $35.75 \mathrm{~s}$ ) in G1A, and 12 and $170 \mathrm{sec}-$ onds (mean $76.17 \mathrm{~s}$ ) in G2A. For Profi II, the time ranged between 20 and 60 seconds (mean $36.67 \mathrm{~s}$ ) in G1B, and 28 and 175 seconds (mean $76.25 \mathrm{~s}$ ) in G2B. Jet Sonic Satelec presented the largest amplitude of time variation, ranging from 23 to $180 \mathrm{sec}-$ onds (mean $51.83 \mathrm{~s}$ ) in G1C and 19 to 334 seconds (mean 123.67 s) in G2C.

No statistically significant difference $(\mathrm{p}=0.088)$ was observed between the control and the two experimental ultrasound devices (Table 1, Graph 1). However, the time required for post removal varied according to the luting agent used. The average times for G1 and G2 were 41.42 and 92.03 seconds, respectively, with significant difference between the groups $(\mathrm{p}=0.001)($ Table 1 , Graph 1$)$.

\section{Discussion}

In endodontic practice, piezoelectric ultrasonic devices have the ability to clean and shape the root canal system; remove silver points, paste, cement, and root canal filling; surgically retro-instrument and, above all, remove intraradicular metallic posts. ${ }^{1,5,7-9,11}$ In this study, as in previous research, ${ }^{4,12}$ 
extracted human premolars were used for post removal by ultrasonic vibration. Although in vitro tests are not always able to reproduce in vivo conditions, they can offer comparative values that may guide clinical procedures.

The use of metallic cast intraradicular posts is beyond question due to the propagation of occlusal forces to the radicular structure that they provide, while the use of prefabricated posts reinforced with either glass-fiber or carbon and cemented with adhesive materials has gained popularity as they present favorable biomechanical properties and an elasticity modulus which is close to that of dentine. ${ }^{15,20}$ Nevertheless, in the case of extensive coronal destruction, mainly of pillar teeth of partially fixed or removable prostheses, metallic cast posts are still recommended. ${ }^{15}$

It is generally agreed that post retention is a major factor in the survival of restorations. ${ }^{8,15,19,20}$ Several factors may affect post retention such as post type ${ }^{17}$ (custom made or prefabricated), post design ${ }^{3,10,13}$ (parallel, tapered, smooth, serrated, threaded), post adaptation to the root canal, cemented depth and cementing medium. ${ }^{1,4,-9,20}$ Regarding the latter condition, a previous study ${ }^{22}$ did not find difference in retentive force when intracanal posts cemented with zinc phosphate- or glass ionomer-based sealers were compared. Another investigation ${ }^{6}$ demonstrated that ultrasonic vibration for 10 minutes reduced the retention of zinc phosphate and glass ionomer sealers in $39 \%$ and $33 \%$, respectively.

Considering the time necessary to dislodge intra-

Table 1 - Mean time (seconds) required for post removal in the groups 1 and 2 .

\begin{tabular}{c|l|c|c|c}
\hline \multicolumn{1}{c|}{ Group } & \multicolumn{1}{c|}{ Subgroups } & $n$ & Mean* & $\begin{array}{c}\text { Standard } \\
\text { Deviation }\end{array}$ \\
\hline \multirow{2}{*}{$\begin{array}{l}\text { 1-Zinc } \\
\text { phosphate } \\
\text { cement }\end{array}$} & 1A- Enac & 12 & $35.75^{\mathrm{ab}}$ & 28.63 \\
\cline { 2 - 5 } & 1B- Profi II & 12 & $36.67^{\mathrm{ab}}$ & 13.09 \\
\cline { 2 - 5 } & 1C- Jet Sonic & 12 & $51.83^{\mathrm{ab}}$ & 41.62 \\
\hline \multirow{2}{*}{$\begin{array}{l}\text { 2-Glass } \\
\text { ionomer } \\
\text { cement }\end{array}$} & 2A- Enac & 12 & $76.17^{\mathrm{ac}}$ & 50.79 \\
\cline { 2 - 5 } & 2B- Profi II & 12 & $76.25^{\mathrm{ac}}$ & 45.06 \\
\cline { 2 - 5 } & 2C- Jet Sonic & 12 & $123.67^{\mathrm{ac}}$ & 107.84 \\
\hline
\end{tabular}

*Similar letters indicate statistically similar values $(p>0.05)$. Different letters indicate statistically different values $(p<0.05)$. radicular posts, some studies ${ }^{5,21}$ showed that posts cemented with zinc phosphate required a rather short period of time (up to 3 minutes) to be dislodged. Conversely, 3 minutes of vibration was not enough to completely release cast posts cemented with glass ionomer cement. ${ }^{17}$

The results of the present study showed that all the cast metallic posts were successfully removed in a short time interval (mean time up to 2 minutes) with the glass ionomer cement having a significant retentive advantage. Considering that the efficiency of an ultrasound device is related to its capacity to break the juncture between root canal walls and post, a similar behavior could be expected for both luting agents. However, glass ionomeric cements present adhesive properties that can increase its retentive abilities when they are used for post cementation. ${ }^{23}$ Besides, the viscoelastic nature attenuates the vibrations and absorbs ultrasonic energy transmitted to the posts. ${ }^{4,20}$

In the present study, the performance of two Brazilian ultrasonic units (Profi II Ceramic and Jet Sonic Satelec) was compared to that of the Japanese gold standard (Enac). It was observed that the time required for complete removal of the intraradicular posts ranged from 12 to 334 seconds. Profi II and Enac had a similar behavior, despite the recent man-

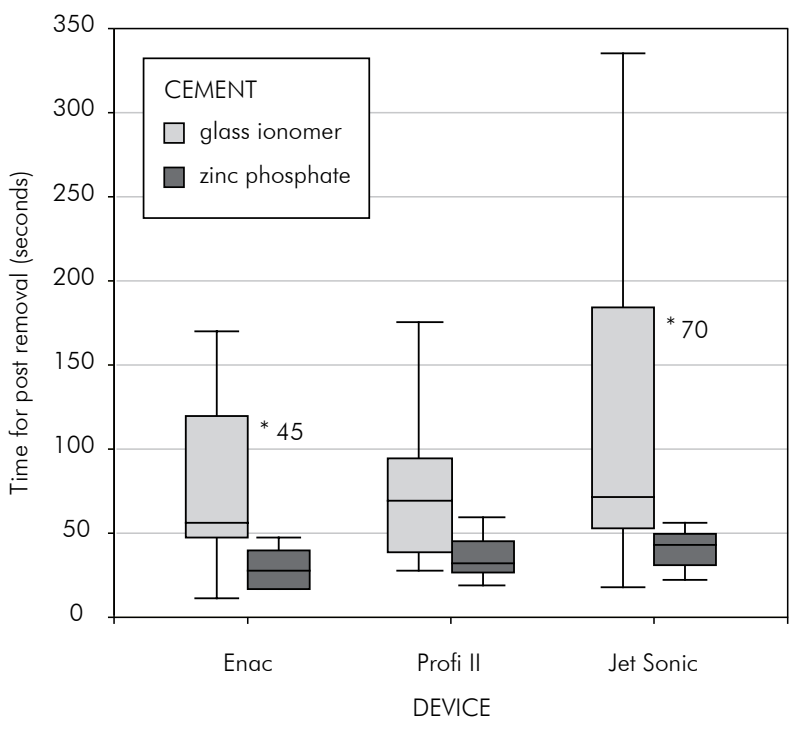

Graph 1 - Time required (in seconds) for post removal for groups and subgroups of the study. 
ufacturer's $20 \%$ increase in the power of the Enac. Although Jet Sonic Satelec required a longer time for post removal, mainly when the glass ionomer cement was used, there were no differences among the ultrasound devices. Large standard deviations have clearly contributed to this result.

Considering that this experiment was rigorously controlled, the differences in structure and composition of the dentine of the individual roots, as previously stated, ${ }^{20}$ might have contributed to this variation. This variability may also be explained due to variables relative to the tested devices, such as the thickness of the quartz crystal plate and the degree of crystal purity. ${ }^{8,17,19}$ Moreover, an oscillation in time was also observed in another study ${ }^{5}$ that evaluated the performance of two ultrasonic units in the removal of intraradicular posts.

In this study and according to Johnson et al. ${ }^{12}$ (1996), Gomes et al. ${ }^{6}$ (2001), and Dixon et al. ${ }^{5}$ (2002), the ultrasound devices were applied to the intraradicular retainer at maximum power on the surrounding and incisal surfaces. Thus, the ultrasonic tip was continuously moved $360^{\circ}$ around the post to induce resonance. An attempt was made to adjust the ultrasound tip to emit an audible sound level to maximize the energy that was transferred to

\section{References}

1. Castrisos T, Abbott PV. A survey of methods used for post removal in specialist endodontic practice. Int Endod J. 2002;35(2):172-80.

2. Chalfin H, Weseley P, Solomon C. Removal of restorative posts for the purpose of nonsurgical endodontic retreatment: report of cases. J Am Dent Assoc. 1990;120(2):169-72.

3. Lopes HP, Siqueira Jr JF, Elias CN. Retratamento endodôntico. In: Lopes HP, Siqueira Jr JF. Endodontia: Biologia e Técnica. $2^{\mathrm{a}}$ ed. Rio de Janeiro: Medsi; 2004. p. 727-85.

4. Buoncristiani J, Seto BG, Caputo AA. Evaluation of ultrasonic and sonic instruments for intraradicular post removal. J Endod. 1994;20(10):486-9.

5. Dixon EB, Kaczkowski PJ, Nicholls JI, Harrington GW. Comparison of two ultrasonic instruments for post removal. J Endod. 2002;28(2):111-5.

6. Gomes APM, Kubo CH, Santos RA, Santos DR, Padilha RQ. The influence of ultrasound on the retention of cast posts cemented with different agents. Int Endod J. 2001;34(2):93-9. the post. ${ }^{17}$ Comparatively to other devices, the Enac appeared to have a greater audible sound, mainly on the incisal surface, corroborating an earlier investigation. ${ }^{5}$

Another approach of this study concerns the inexistence of radicular damage after the use of ultrasounds at maximum power, which so far confirms the safety of the ultrasonic technique and reduced clinical occurrence of radicular fracture. ${ }^{1,9}$ Further research is necessary to confirm the effect of ultrasonic times longer than those used in this study.

\section{Conclusions}

The ultrasonic units Prof II Ceramic and Jet Sonic Satelec presented performances similar to that of the international Gold standard Enac in the removal of intraradicular cast posts, although a large variability in the length of time was observed.

All the metallic cast posts cemented with glass ionomer or zinc phosphate sealers were successfully removed in a short time interval (mean time up to 2 minutes).

The luting agents exerted a greater influence on the time required for post removal than the origin of the ultrasonic units.

7. Smith BJ. Removal of fractured posts using ultrasonic vibration: an in vivo study. J Endod. 2001;27(10):632-4.

8. Stamos DE, Gutmann JL. Survey of endodontic retreatment methods used to remove intraradicular posts. J Endod. 1993;19(7):366-9.

9. Abbott PV. Incidence of root fractures and methods used for post removal. Int Endod J. 2002;35(1):63-7.

10. Garrido AD, Fonseca TS, Alfredo E, Silva-Sousa YT, SousaNeto MD. Influence of ultrasound, with and without water spray cooling, on removal of posts cemented with resin or zinc phosphate cements. J Endod. 2004;30(3):173-6.

11. Imura N, Zuolo ML. Remoção de retentor intra-radicular com aparelho de ultra-som. Rev Assoc Paul Cir Dent. 1997;51(3):262-7.

12. Johnson WT, Leary JM, Boyer DB. Effect of ultrasonic vibration on post removal in extracted human premolar teeth. J Endod. 1996;22(9):487-8.

13. Lopes HP, Elias CN, Costa Filho AS, Chiminazzo MA. Desgaste intra-radicular determinado pela remoção de pinos me- 
tálicos, através de instrumentos rotatórios. Rev Bras Odontol. 1993;50(3):20-5

14. Stabholz A, Friedman S. Endodontic retreatment - case selection and technique. Part 2: Treatment planning for retreatment. J Endod. 1988;14(12):607-14.

15. Vasconcellos AB, Lopes HP. Retentores intra-radiculares. In: Lopes HP, Siqueira Jr JF. Endodontia: Biologia e Técnica. $2^{\text {a }}$ ed. Rio de Janeiro: Medsi; 2004. p. 696-706.

16. Berbert A, Tanomaru Filho M, Ueno AH, Bramante CM, Ishikiriama A. The influence of ultrasound in removing intraradicular posts. Int Endod J. 1995;28(1):54-6.

17. Silva MR, Biffi JC, Mota AS, Fernandes Neto AJ, Neves FD. Evaluation of intracanal post removal using ultrasound. Braz Dent J. 2004;15(2):119-26.

18. Krell KV, Jordan RD, Madison S, Aquilino S. Using ultrasonic scalers to remove fractured root posts. J Prosthet Dent. 1986;55(1):46-9.
19. De Deus QD. Endodontia. 5 ${ }^{\mathrm{a}}$ ed. Rio de Janeiro: Medsi; 1992.

20. Hauman CH, Chandler NP, Purton DG. Factors influencing the removal of posts. Int Endod J. 2003;36(10):687-90.

21. Oliveira MRS, Biffi JCG, Mota AS, Maniglia CAG. Avaliação da remoção de pinos intra-radiculares pré-fabricados através de técnica ultra-sônica. Rev Assoc Paul Cir Dent. 1999;53(5):3727.

22. Chan FW, Harcourt JK, Brockhurst PJ. The effect of post adaptation in the root canal on retention of posts cemented with various cements. Aust Dent J. 1993;38(1):39-45.

23. Tjan AH, Tjan AH, Greive JH. Effects of various cementation methods on the retention of prefabricated posts. J Prosthet Dent. 1987;58(3):309-13. 